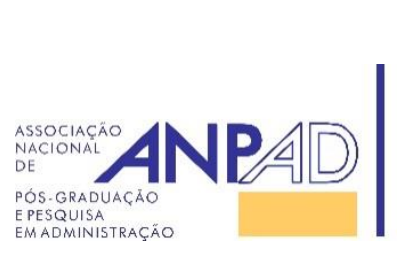

Disponível em

http://www.anpad.org.br/rac

RAC, Rio de Janeiro, v. 21, n. 6, art. 2,

pp. 764-787, Novembro/Dezembro, 2017 http://dx.doi.org/10.1590/1982-7849rac2017160284

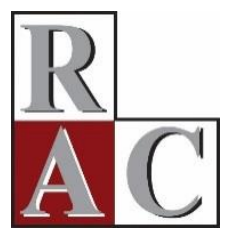

$(\mathrm{cc}) \mathrm{EY}$

\title{
As Organizações e a Felicidade no Trabalho: Uma Perspectiva Integrada
}

Organizations and Happiness at Work: An Integrated Perspective

Gisela Sender ${ }^{1}$ Denise Fleck $^{1}$

Universidade Federal do Rio de Janeiro ${ }^{1}$

Artigo recebido em 26.09.2016. Última versão recebida em 09.06.2017. Aprovado em 13.06.2017. Publicado online em 11.10.2017. 


\title{
Resumo
}

A despeito do grande número de estudos relacionados à felicidade derivada do trabalho nas organizações, estes são dispersos, divergentes e, portanto, pouco conclusivos. Isto traz dificuldades para a evolução da pesquisa sobre este tópico e para a tomada de decisões no dia a dia quanto ao tema nas empresas. Tomando por base uma revisão de literatura abrangente, este artigo propõe uma perspectiva que engloba o conhecimento desenvolvido sobre o assunto até o momento. Para tanto, parte de três questões: como se define felicidade no trabalho; o efeito da felicidade no trabalho nos resultados das empresas; e o que torna os indivíduos felizes no trabalho. A proposta de perspectiva integrada utiliza os princípios de Kahneman e Riis (2005), concentrando-se principalmente nos antecedentes da felicidade no trabalho e seus possíveis impactos no comportamento do indivíduo na organização.

Palavras-chave: felicidade no trabalho; satisfação; motivação; bem-estar; antecedentes.

\begin{abstract}
Despite the large number of studies on happiness at work in organizations, they are disperse and divergent and thus inconclusive. This makes the evolution of research on this topic and practicioners' decision-making regarding the happiness at work difficult. Based on a comprehensive literature review, this article proposes a perspective that encompasses the knowledge developed so far. To do so, it explores three issues: how happiness at work has been defined; the impact of happiness at work on organizational performance; and, what makes people happy at work. The integrated perspective this paper advances draws on the principles from Kahneman and Riis (2005), mainly focusing on antecedents of happiness at work and their impact on individual behavior in the organization.
\end{abstract}

Key words: happiness at work; job satisfaction; motivation; well-being; antecedents. 


\section{Introdução}

O pesquisador de organizações que decide estudar o tema felicidade no trabalho encontra questionamentos que, segundo Saks e Gruman (2014), até hoje não têm respostas conclusivas. Ainda não está bem definido na literatura o que é a felicidade no trabalho e como esta pode ser medida (Spicer \& Cederström, 2015). Também não se conhece seu real efeito nos resultados das empresas; nem se sabe ao certo o que a causa e nem qual é o papel das ações das organizações na obtenção de tal felicidade por parte dos indivíduos (Saks \& Gruman, 2014).

A falta de respostas conclusivas a estas questões não está ligada a um número reduzido de pesquisas no tema. Ao contrário, existe uma vasta literatura sobre o assunto, porém esta é difusa e desfocada (Danna \& Griffin, 1999) e de difícil generalização (Sant'anna, Paschoal, \& Gosendo, 2012), não havendo, portanto, uma unidade de conceitos nem uma convergência de resultados. Essa falta de alinhamento faz com que os acadêmicos não produzam conhecimento consistente que possa contribuir para a evolução do entendimento geral do assunto e auxiliar os gestores em relação ao tema.

Sendo assim, o objetivo deste artigo é propor uma perspectiva dos antecedentes da felicidade no trabalho nas organizações e suas consequências no comportamento dos indivíduos abrangendo o conhecimento gerado até o momento, de forma a ajudar a direcionar a evolução da pesquisa das organizações nesse assunto. Para isso, o estudo parte de três questionamentos: (a) como se define a felicidade no trabalho; (b) qual o efeito da felicidade no trabalho nos resultados das empresas; e (c) o que faz com que os indivíduos sejam felizes no trabalho.

A próxima seção descreve os procedimentos metodológicos da revisão de literatura. As seções seguintes abordam os três questionamentos acima, respectivamente: as principais noções associadas à felicidade no trabalho; os impactos da felicidade no trabalho para as organizações; e os aspectos que influenciam a felicidade no trabalho, compreendendo antecedentes que se originam tanto no indivíduo quanto na organização. Por fim, apresenta-se uma proposta de perspectiva integrada do conhecimento produzido até o momento, seguida da discussão das implicações do estudo para a pesquisa e para a prática.

\section{Procedimentos Metodológicos}

A revisão de literatura que serviu de base ao presente trabalho se realizou em duas etapas. Com o objetivo de traçar um panorama o mais abrangente possível sobre o tema, a primeira etapa teve um caráter exploratório, a partir da literatura de diversas disciplinas, com artigos de periódicos de Administração (Gestão, Comportamento Organizacional e RH), Psicologia, Economia, Sociologia, Engenharia de Produção e áreas menos correlatas (Marketing e Operações). Esta etapa compreendeu os seguintes passos:

1. Busca do termo felicidade no trabalho e seu equivalente em inglês happiness at work nas bases de dados EBSCOhost, ProQuest, Google Scholar e ScienceDirect, por ordem de relevância, obtendo-se artigos que serviram como ponto de partida.

2. Aplicação de uma abordagem do tipo snowball - normalmente aplicada à amostragem, caracterizase pelo uso de um conjunto inicial de dados como uma base para localizar novas fontes de dados (Given, 2008), buscando as referências mais citadas (visando cobrir os principais estudos de cada tema) e outras palavras-chave frequentes relacionadas ao tema.

Em função da ampla abrangência identificada na primeira etapa, a segunda consistiu em quantificar o uso dos conceitos encontrados na literatura e que servem de base para os estudos, a partir 
da consulta a artigos das bases de dados da Elsevier, utilizando os respectivos termos, em qualquer data e disciplina.

\section{Conceituando a Felicidade no Trabalho}

\section{Contexto}

No século XVIII, Adam Smith, pai do capitalismo industrial, declarou que é da natureza humana abominar o trabalho e, portanto, os indivíduos seriam naturalmente preguiçosos e só trabalhariam por dinheiro (Smith, 1776). Essa ideia influenciou todo o modo de pensar sobre as relações de trabalho nos séculos seguintes (Ariely, 2013; Schwartz, 2015a, 2015b; Smith, 1776; Spencer, 2014).

No final do século XIX e início do século XX, as ideias de Adam Smith ajudaram a moldar o movimento de administração científica, desenvolvido por Frederick W. Taylor, que tinha como objetivo criar um sistema eficiente de manufatura através da fragmentação do trabalho, redução da demanda de habilidades, alto controle e separação entre conceito e execução (Taylor, 1990).

Um pouco mais tarde, os estudos de Hawthorne (fábrica da Bell Telephone Western Electric, em Chicago) tornaram-se, segundo Brannigan e Zwerman (2001), a mais importante investigação da dimensão humana nas relações industriais no início do século XX. Precisando lidar com um crescimento de demanda sem precedentes, a empresa criou uma divisão de pesquisa para conduzir experimentos sobre os efeitos de várias condições de trabalho na produtividade. No experimento de iluminação, mesmo quando esta era reduzida, os resultados melhoravam, indicando que as mudanças físicas tinham menor impacto do que o efeito psicológico de saber que a gestão buscava melhorar o ambiente de trabalho. Foi reconhecida, então, a importância de considerar a situação total dos indivíduos (vida emocional, valores culturais e aspirações pessoais) no trabalho e fora dele (Brannigan \& Zwerman, 2001).

Desde então, executivos e acadêmicos de humanidades e ciências sociais mantêm um contínuo interesse em compreender a influência desses fatores na produtividade do indivíduo (Bagtasos, 2011; Ledford, 1999; Spicer \& Cederström, 2015). No entanto, a evolução do conhecimento de um fenômeno requer o desenvolvimento de construtos associados a instrumentos de medição válidos e confiáveis (Paschoal \& Tamayo, 2008), ou seja, a mensuração da felicidade é um ponto crucial no avanço da sua compreensão (Dolan, 2015). Assim, nas últimas quatro décadas, foram desenvolvidos vários construtos, com diferentes denominações, que permitem operacionalizar a noção de felicidade no trabalho.

\section{Principais termos utilizados pela literatura}

A Tabela 1 apresenta os principais termos utilizados na literatura ligados à felicidade no trabalho, de acordo com Fisher (2010). 
Tabela 1

\section{Principais Termos Ligados à Felicidade no Trabalho}

\begin{tabular}{|c|c|}
\hline Termos & Descrição \\
\hline $\begin{array}{l}\text { Job Satisfaction } \\
\text { (satisfação) }\end{array}$ & $\begin{array}{l}\text { A primeira definição foi feita por Hoppock (1935), como uma combinação de } \\
\text { circunstâncias (psicológicas, fisiológicas e ambientais) que fazem o indivíduo se } \\
\text { considerar satisfeito com o seu trabalho. Mais tarde foi definido por Locke } \\
\text { (1969) como um estado emocional resultante da avaliação que o indivíduo faz do } \\
\text { seu trabalho. }\end{array}$ \\
\hline $\begin{array}{l}\text { Job Involvement } \\
\text { (envolvimento) }\end{array}$ & $\begin{array}{l}\text { Segundo Lodahl e Kejnar (1965), relaciona-se ao grau de identificação } \\
\text { psicológica do indivíduo com seu trabalho ou à importância do trabalho para sua } \\
\text { autoimagem. }\end{array}$ \\
\hline $\begin{array}{l}\text { Organizational Commitment } \\
\text { (comprometimento) }\end{array}$ & $\begin{array}{l}\text { De acordo com Mowday, Porter e Steers (1982), uma ligação psicológica com a } \\
\text { organização leva o indivíduo a internalizar os objetivos da empresa e } \\
\text { voluntariamente se comportar de forma a alcançá-los, o que seria uma visão } \\
\text { afetiva. Além desta visão, Swailes (2002) cita também o comprometimento } \\
\text { instrumental (baseado em fatores socioeconômicos) e o normativo (sentimentos } \\
\text { de lealdade e obrigação). }\end{array}$ \\
\hline $\begin{array}{l}\text { Employee engagement } \\
\text { (engajamento) }\end{array}$ & $\begin{array}{l}\text { Inicialmente proposto por Kahn (1990), o funcionário engajado é aquele atrelado } \\
\text { ao desempenho dos seus papéis no trabalho, de forma física, cognitiva e } \\
\text { emocional. O assunto passou cerca de } 20 \text { anos sem muitas referências, tendo sido } \\
\text { retomado por volta de } 2010 \text { (Saks \& Gruman, 2014). }\end{array}$ \\
\hline $\begin{array}{l}\text { Flow state } \\
\text { (estado de fluxo) }\end{array}$ & $\begin{array}{l}\text { Ligado à experiência do indivíduo quando executa uma tarefa, o construto foi } \\
\text { proposto por Csikszentmihalyi (1991) e tem como premissa ser positivo o } \\
\text { indivíduo se concentrar integralmente nas tarefas que desempenha. }\end{array}$ \\
\hline $\begin{array}{l}\text { Work motivation } \\
\text { (motivação) }\end{array}$ & $\begin{array}{l}\text { Conceito mais amplo, influencia as atitudes e o comportamento dos indivíduos } \\
\text { no ambiente de trabalho (Ambrose \& Kulik, 1999). A motivação pode ser } \\
\text { intrínseca (os indivíduos realizam algo espontaneamente, pois acham a atividade } \\
\text { interessante por si só, como no estado de fluxo) e/ou extrínseca (os indivíduos } \\
\text { percebem consequências tangíveis pela realização da atividade, tais como } \\
\text { recompensas materiais ou verbais) (Gagné \& Deci, 2005). }\end{array}$ \\
\hline $\begin{array}{l}\text { Well-being } \\
\text { (bem-estar) }\end{array}$ & $\begin{array}{l}\text { Assim como a motivação, este construto também é utilizado de uma forma mais } \\
\text { ampla no contexto do trabalho. É chamado de bem-estar afetivo, de forma a } \\
\text { distingui-lo da saúde física (Danna \& Griffin, 1999) e pode ser diferenciado entre } \\
\text { bem-estar objetivo (relaciona-se com condições objetivas, tais como conforto e } \\
\text { riqueza) e subjetivo (reflete a experiência do indivíduo e sua avaliação da própria } \\
\text { condição) (Diener, 1984). }\end{array}$ \\
\hline
\end{tabular}

Conforme sugerem Albuquerque e Tróccoli (2004), as definições existentes na literatura não são totalmente claras e não há um consenso entre os pesquisadores do assunto, o que pode ser visto pela multiplicidade de termos da Tabela 1, bem como pela existência de outros mais recentes, tais como Thriving, Vigor e Flourishing (Fisher, 2010). Pode-se perceber, também, pelas descrições apresentadas, que há uma sobreposição de conceitos. Além disso, a frequência com que os diversos termos são empregados não é uniforme.

Job satisfaction é o termo mais utilizado, conforme pode ser verificado nas estatísticas de uso dos termos em diversas áreas de conhecimento (vide Tabela 2). É digna de nota a quantidade de artigos sobre job satisfaction em Ciências da Saúde, que, de uma forma geral, referem-se: (a) ao impacto do assunto em stress e burnout, causando doenças; e (b) à atividade propriamente dita dos profissionais de medicina e enfermagem. 
Tabela 2

Principais Termos e sua Utilização, por Área de Conhecimento

\begin{tabular}{lccccc}
\hline Termo $^{\mathrm{a}}$ & \# artigos & Life Sciences & Health Sciences & Physical Sciences & $\begin{array}{c}\text { Social Sciences \& } \\
\text { Humanities }\end{array}$ \\
\hline Satisfaction & 31.937 & $5 \%$ & $54 \%$ & $6 \%$ & $35 \%$ \\
Well-being & 6.645 & $5 \%$ & $37 \%$ & $8 \%$ & $49 \%$ \\
Commitment & 4.807 & $4 \%$ & $17 \%$ & $8 \%$ & $71 \%$ \\
Engagement & 2.402 & $2 \%$ & $21 \%$ & $10 \%$ & $67 \%$ \\
Motivation & 1.084 & $4 \%$ & $25 \%$ & $8 \%$ & $63 \%$ \\
Involvement $^{\text {c }}$ & 643 & $3 \%$ & $17 \%$ & $8 \%$ & $72 \%$ \\
Flow State $^{b}$ & 500 & $3 \%$ & $11 \%$ & $19 \%$ & $66 \%$ \\
\hline Total & 48.081 & $5 \%$ & $44 \%$ & $7 \%$ & $44 \%$ \\
\hline
\end{tabular}

Nota. Pesquisa realizada na base de dados Elsevier. (n.d.). Scopus database. Retrieved August 30, 2016, from http://www.sciencedirect.com/science/search, selecionando apenas artigos e utilizando os campos Title, Abstract e Keywords. ${ }^{a}$ Para caracterizar o termo em questão, que pode ser utilizado em outros contextos, foram acrescidos, para fins de busca, as palavras work, job, organizational e/ou employee ${ }^{\mathrm{b}}$ Neste caso específico, foram utilizados também os termos state of flow e flow experience, além de acrescentado o nome do autor à busca (em todos os campos), pois especificamente em Physical Sciences há outros termos semelhantes.

\section{A felicidade no trabalho}

De maneira geral, é difícil encontrar explicitamente a palavra felicidade nas principais linhas de estudo sobre gestão de pessoas e comportamento organizacional. Normalmente são utilizados os termos citados na Tabela 2, considerados mais objetivos e acadêmicos (Bendassolli, 2007; Paschoal, Torres, \& Porto, 2010). Para fins de comparação, ao se buscar os termos happiness at work ou work happiness, utilizando procedimento idêntico àquele que produziu a Tabela 2, apenas 49 artigos foram encontrados.

No entanto, segundo Paschoal, Torres e Porto (2010), o uso do termo felicidade oferece vantagens, pois envolve elementos filosóficos e conceituais que normalmente não são considerados nos estudos sobre o tema, trazendo uma conotação positiva. Em linha com Fisher (2010) e Sousa e Porto (2015), este artigo considera a felicidade no trabalho como um conceito guarda-chuva, englobando os demais construtos e conceitos apresentados nesta seção.

Além disso, em conformidade com as ideias de Macey e Schneider (2008), este artigo também considera a felicidade no trabalho como um estado psicológico positivo do indivíduo, que influencia seu comportamento e que pode levar a consequências positivas para as organizações. Tal perspectiva é baseada no Modelo de Características da Função (Hackman \& Oldham, 1976) que tem o estado psicológico como núcleo causal - o indivíduo experimenta, através desse estado, um afeto positivo, que serve de incentivo para que ele tenha um bom desempenho, gerando o que os autores chamam de "ciclo de autoperpetuação da motivação positiva do trabalho alimentado por recompensas autogeradas" (Hackman \& Oldham, 1976, p. 256). As consequências do estado psicológico da felicidade no trabalho são apresentadas na próxima seção.

\section{Impacto da Felicidade no Trabalho no Desempenho das Organizações}

O impacto da felicidade dos indivíduos nos resultados das organizações é também objeto de controvérsia em estudos sobre o tema. Segundo Weiss e Cropanzano (1996), o efeito da felicidade no desempenho é considerado o Santo Graal da pesquisa neste assunto. Desde os estudos de Hawthorne, 
tem prevalecido tanto nas organizações como nos meios acadêmicos a noção de que indivíduos mais felizes no trabalho são mais produtivos (Ledford, 1999).

No entanto, os estudos acadêmicos têm encontrado dificuldade em confirmar esta relação (Fisher, 2003; Ledford, 1999). O estudo de Brayfield e Crockett (1955) foi o primeiro a concluir que a felicidade no trabalho não implica um desempenho excepcional e que a produtividade é um objetivo periférico nas organizações. A partir de então, vários estudos foram desenvolvidos em torno do que é chamado de happy-productive worker thesis, gerando inúmeros debates nos estudos organizacionais (Ledford, 1999; Wright \& Staw, 1999a, 1999b).

Como também pode ser visto na Tabela 3, além da produtividade, outros impactos positivos para as organizações também foram propostos: melhoria de índices de turnover e absenteísmo, com redução de doenças (Staw, Bell, \& Clausen, 1986; Weiss \& Cropanzano, 1996; Wright \& Huang, 2012); e maior satisfação dos clientes, através de melhor atendimento pelos funcionários (Fisher, 2003; Spicer \& Cederström, 2015).

Tabela 3

Impactos da Felicidade no Trabalho X Construtos

\begin{tabular}{|c|c|c|}
\hline Consequência & Construto & Referência \\
\hline$\downarrow$ Absenteísmo & Commitment & Mowday, Steers e Porter (1996) \\
\hline$\downarrow$ Acidentes & $\begin{array}{l}\text { Satisfaction } \\
\text { Engagement }\end{array}$ & Harter, Schmidt e Hayes (2002) \\
\hline \multirow[t]{2}{*}{$\uparrow$ Lucratividade } & Engagement & Gallup (2013); Hughes e Rog (2008) \\
\hline & Satisfaction & Harter et al. (2002) \\
\hline \multirow{4}{*}{$\begin{array}{l}\text { 个 Produtividade/ } \\
\text { Desempenho }\end{array}$} & Commitment & Mowday et al. (1996) \\
\hline & Engagement & $\begin{array}{l}\text { Gallup (2013); Harter et al. (2002); Hughes e Rog (2008); } \\
\text { Shuck, Reio e Rocco (2011) }\end{array}$ \\
\hline & Satisfaction & $\begin{array}{l}\text { Brayfield e Crockett (1955); Fisher (2003); Harter et al. } \\
\text { (2002); Spicer e Cederström (2015); Weiss e Cropanzano } \\
\text { (1996) }\end{array}$ \\
\hline & Well-being & Wright e Huang (2012) \\
\hline 个 Qualidade do serviço & Engagement & Hughes e Rog (2008) \\
\hline 个 Satisfação do cliente & Engagement & Gallup (2013); Harter et al. (2002) \\
\hline 个 Saúde do indivíduo & Well-being & Wright e Huang (2012) \\
\hline \multirow[t]{5}{*}{$\downarrow$ Turnover } & Commitment & Mowday et al. (1982); Mowday et al. (1996) \\
\hline & Engagement & Hughes e Rog (2008); Shuck et al. (2011) \\
\hline & Involvement & Wickert (1951) \\
\hline & Satisfaction & Harter et al. (2002) \\
\hline & Well-being & Wright e Huang (2012) \\
\hline$\uparrow$ Vendas & Engagement & Hughes e Rog (2008) \\
\hline
\end{tabular}

Nota. $\uparrow=$ Incremento; $\downarrow=$ Redução. Muito embora não se tenha chegado a uma conclusão categórica a respeito da relação entre a felicidade no trabalho, independentemente do construto empregado e de seus impactos na organização, essa questão permanece relevante tanto no âmbito acadêmico como no da prática. Neste sentido, faz-se necessário compreender o que influencia a felicidade no trabalho dos indivíduos nas organizações.

Com base em alguns exemplos de artigos sobre o tema, a Tabela 3 também ilustra a variedade de construtos utilizados em estudos que buscam identificar a relação entre a felicidade no trabalho e esses 
indicadores organizacionais. A exemplo do estudo de Zelenski, Murphy e Jenkins (2008), as investigações sobre os impactos que diferentes conceitos ligados à felicidade no trabalho poderiam exercer sobre a produtividade têm produzido resultados inconclusivos, muitas vezes atribuídos a diferenças nos conceitos e medições empregados.

\section{Buscando a Felicidade no Trabalho}

Dois tipos de estudo buscam entender o que possibilita o alcance da felicidade no trabalho: os que propõem e/ou testam a influência de elementos isolados ou grupos deles; e os que desenvolvem teorias e/ou modelos para explicar de uma forma mais ampla o fenômeno. Em ambos os casos a origem dos antecedentes da felicidade do trabalho pode se situar no próprio indivíduo, cujas características poderiam influenciar seu grau de felicidade no trabalho; e na organização, cujas iniciativas podem tornar o indivíduo mais feliz. Estas variações serão apresentadas a seguir.

\section{Antecedentes da felicidade no trabalho - elementos}

\section{Indivíduo}

Os antecedentes com foco no indivíduo foram identificados principalmente em estudos de biologia, psicologia e sociologia e são apresentados na Tabela 4.

Tabela 4

Principais Elementos Antecedentes da Felicidade no Trabalho

\begin{tabular}{lll}
\hline Nível de análise & Antecedentes & Referências \\
\hline Indivíduo & Carga genética & $\begin{array}{l}\text { Arvey, Bouchard, Segal e Abraham (1989); Lykken e } \\
\text { Tellegen (1996); Schnittker (2008); Sosis (2014) }\end{array}$ \\
\cline { 2 - 3 } & Traços de personalidade & $\begin{array}{l}\text { Handa e Gulati (2014); Ilies e Judge (2003); Judge, } \\
\text { Heller e Mount (2002); Staw e Ross (1985) }\end{array}$ \\
\cline { 2 - 3 } & Vocação (chamado) & $\begin{array}{l}\text { Bellah, Madsen, Sullivan, Swidler e Tipton (1985); } \\
\text { Wrzesniewski, McCauley, Rozin e Schwartz (1997) }\end{array}$ \\
\cline { 2 - 3 } & Rriação & Rones (2016); Schnittker (2008) \\
\cline { 2 - 3 } & Significado do trabalho & $\begin{array}{l}\text { Cartwright e Holmes (2006); Dejours (2004); Frankl } \\
\text { (1984); Morin (2001); Morin, Tonelli e Pliopas (2007); } \\
\text { Rosso, Dekas e Wrzesniewski (2010); Wrzesniewski e } \\
\text { Dutton (2001) }\end{array}$ \\
\cline { 2 - 3 } & Inteligência & Ganzach (1998) \\
\cline { 2 - 3 } & Variáveis demográficas ${ }^{\mathrm{a}}$ & $\begin{array}{l}\text { Dolan, Peasgood e White (2008); Lok e Crawford } \\
\text { (2004) }\end{array}$ \\
& \\
\hline
\end{tabular}


Tabela 4 (continuação)

\begin{tabular}{|c|c|c|c|}
\hline \multicolumn{2}{|c|}{ Nível de análise } & \multirow{2}{*}{$\begin{array}{l}\text { Antecedentes } \\
\begin{array}{l}\text { Desenvolvimento e } \\
\text { treinamento }\end{array}\end{array}$} & \multirow{2}{*}{$\begin{array}{l}\text { Referências } \\
\text { Baruch (2006); Eisenberger, Huntington, Hutchison e } \\
\text { Sowa (1986); M. K. Jones, Jones, Latreille e Sloane } \\
\text { (2009); Walton (1973) }\end{array}$} \\
\hline Organização & Empresa & & \\
\hline & & Condições físicas & $\begin{array}{l}\text { Eisenberger et al. (1986); Morgeson e Humphrey } \\
\text { (2006); Walton (1973) }\end{array}$ \\
\hline & & Jornada de trabalho & $\begin{array}{l}\text { Aronsson (1989); Dejours, Abdoucheli e Jayet (1993); } \\
\text { Leslie, Manchester, Park e Mehng (2012); Morgeson e } \\
\text { Humphrey (2006); Oliveira e Cavazotte (2013); Spector } \\
\text { e Jex (1998); Walton (1973) }\end{array}$ \\
\hline & & Justiça & Eisenberger et al. (1986); Walton (1973) \\
\hline & & Remuneração & Eisenberger et al. (1986); Walton (1973) \\
\hline & & Segurança & $\begin{array}{l}\text { Bose e Sampath (2016); Kets de Vries e Balazs (1997); } \\
\text { Eisenberger } \text { et al. (1986) }\end{array}$ \\
\hline & & Cultura organizacional & $\begin{array}{l}\text { Boxx, Odom e Dunn (1991; Fernandes e Zanelli (2006); } \\
\text { Lund (2003); Odom, Boxx e Dunn (1990) }\end{array}$ \\
\hline & Função & Controle/autonomia & $\begin{array}{l}\text { Aronsson (1989); Csikszentmihalyi (1991); Hackman e } \\
\text { Oldham (1976); Karasek (1989); Morgeson e Humphrey } \\
\text { (2006) }\end{array}$ \\
\hline & & $\begin{array}{l}\text { Variedade de atividades e } \\
\text { habilidades }\end{array}$ & $\begin{array}{l}\text { Dejours (2004); Hackman e Oldham (1976); Johansson } \\
\text { (1989); Morgeson e Humphrey (2006); Walton (1973) }\end{array}$ \\
\hline & & $\begin{array}{l}\text { Equilíbrio entre } \\
\text { complexidade e capacidade }\end{array}$ & Csikszentmihalyi (1991); Morgeson e Humphrey (2006) \\
\hline & & Feedback claro e imediato & $\begin{array}{l}\text { Csikszentmihalyi (1991); Hackman e Oldham (1976); } \\
\text { Morgeson e Humphrey (2006) }\end{array}$ \\
\hline & & $\begin{array}{l}\text { Relevância, significância e } \\
\text { identidade }\end{array}$ & $\begin{array}{l}\text { Hackman e Oldham (1976); Morgeson e Humphrey } \\
\text { (2006) }\end{array}$ \\
\hline & & $\begin{array}{l}\text { Possibilidade de alteração } \\
\text { do desenho da função }\end{array}$ & $\begin{array}{l}\text { Dejours (2004); Handa e Gulati (2014); Wrzesniewski e } \\
\text { Dutton (2001) }\end{array}$ \\
\hline & Pessoas & Relações com gestor & $\begin{array}{l}\text { Carasco-Saul, Kim e Kim (2015); Dejours (2004); } \\
\text { Karasek (1989); Lennerlöf (1989); Li e Liao (2014). }\end{array}$ \\
\hline & & Relações com grupo & $\begin{array}{l}\text { Dejours (2004); Johnson (1989); Kirmeyer e Lin (1987); } \\
\text { Paschoal et al. (2010) }\end{array}$ \\
\hline
\end{tabular}

Nota. ${ }^{a}$ Idade, número de anos na posição, qualificação, sexo, entre outros.

Pela visão biológica, de acordo com estudos de hereditariedade, os eventos da vida (positivos e negativos) têm um efeito temporário - os indivíduos se adaptam a eles, retornando a um nível predeterminado de felicidade média (set point) (Arvey, Bouchard, Segal, \& Abraham, 1989; Lykken \& Tellegen, 1996; Schnittker, 2008; Sosis, 2014).

Já pela perspectiva psicológica, características pessoais, tais como traços de personalidade (Handa \& Gulati, 2014; Ilies \& Judge, 2003; Judge, Heller, \& Mount, 2002; Staw \& Ross, 1985), vocação (Bellah, Madsen, Sullivan, Swidler, \& Tipton, 1985; Wrzesniewski, McCauley, Rozin, \& Schwartz, 1997) e inteligência (Ganzach, 1998), impactam a forma de o indivíduo perceber o trabalho. A influência da família, principalmente na infância, e os valores transmitidos em relação ao trabalho (R. Jones, 2016; Schnittker, 2008), assim como outras variáveis demográficas como idade e sexo (Dolan, Peasgood, \& White, 2008; Lok \& Crawford, 2004), também são relevantes nesta percepção. 
Finalmente, sob o prisma sociológico, o significado do trabalho como forma de inserção das pessoas na sociedade e criação de identidade influencia como o indivíduo se relaciona com o trabalho.

\section{Organizações}

As chamadas variáveis situacionais, ligadas às organizações, são estudadas há mais tempo do que as variáveis pessoais (Ilies \& Judge, 2003; Staw \& Ross, 1985), o que leva a um maior número de elementos relacionados a este nível de análise. Estes elementos, também apresentados na Tabela 4, relacionam-se basicamente a três dimensões das organizações: (a) empresa, enquanto entidade com políticas e práticas; (b) função desempenhada; e (c) pessoas que lá trabalham e com quem o indivíduo se relaciona.

Devido a sua quantidade, os elementos identificados foram agrupados e alocados em cada uma das três dimensões, a partir de uma codificação dos diferentes termos encontrados. Por exemplo, salário, pagamento, benefícios, retribuição material, incentivos, compensação e disponibilidade de dinheiro foram agrupados no antecedente remuneração, da categoria empresa.

Outros antecedentes codificados no nível da empresa estão ligados às políticas normalmente definidas pela área de recursos humanos (RH), tais como desenvolvimento/treinamento, jornada e condições físicas de trabalho. Já antecedentes como justiça e segurança relacionam-se à percepção do indivíduo quanto às ações tomadas pela empresa como um todo, ultrapassando as fronteiras de RH. A cultura organizacional também tem papel importante, uma vez que há certos tipos de cultura mais favoráveis à felicidade no trabalho, normalmente ligados a ambientes mais abertos e dinâmicos.

Quanto à função, há elementos ligados tanto ao seu desenho (job design) quanto à sua execução (job crafting). O principal elemento ligado ao desenho da função, que Dejours (2004) denomina trabalho prescrito, diz respeito à autonomia ou nível de controle no que tange ao seu exercício. Também constituem elementos de destaque no desenho da função: evitar a monotonia da tarefa a ser executada, assegurar à mesma um nível adequado de complexidade, dotar de clareza o que deve ser feito e proporcionar transparência quanto ao desempenho alcançado. Já durante a execução da função, que Dejours (2004) chama de trabalho real, poder-se-ia ajustar o desenho original, incluindo melhorias nas atividades que contribuam para a felicidade no trabalho.

Por fim, "as pessoas precisam de pessoas" (Davidoff, 1983, p. 667), portanto, as relações agradáveis com outros indivíduos também são uma fonte de felicidade no trabalho (Fisher, 2010). Assim, há o impacto das relações com os gestores/líderes e com o grupo no qual o indivíduo se insere, já que a atenuação de formas antigas de coesão social (vilas, vizinhanças, igrejas, etc.) fez com que a interação no ambiente de trabalho se tornasse uma das poucas fontes remanescentes de contato estável e contínuo fora do ambiente familiar (Johnson, 1989).

\section{Antecedentes da felicidade no trabalho - teorias/modelos}

As diversas disciplinas envolvidas com o estudo de felicidade no trabalho também buscaram desenvolver teorias/modelos com o objetivo de explicar o fenômeno de forma mais ampla. Estas são apresentadas na Tabela 5, sendo que algumas delas englobam vários dos elementos apresentados anteriormente. 
Tabela 5

Principais Teorias/Modelos Antecedentes da Felicidade no Trabalho

\begin{tabular}{|c|c|c|c|}
\hline \multicolumn{2}{|c|}{ Nível de análise } & Teoria/Modelo & Autores \\
\hline \multirow[t]{5}{*}{ Indivíduo } & & Teoria das Necessidades & Maslow (1943) \\
\hline & & Teoria da Motivação-Higiene & Herzberg, Mausner e Bloc (1959) \\
\hline & & Psicodinâmica do Trabalho & Dejours (2004) \\
\hline & & Psicologia Positiva & Seligman (2002) \\
\hline & & Economia da felicidade & Frey e Stutzer (2002) \\
\hline \multirow[t]{5}{*}{ Organização } & Empresa & Qualidade de Vida Total & Walton (1973) \\
\hline & & Suporte Organizacional Percebido & Eisenberger et al. (1986) \\
\hline & Função & Modelo das Características da Função & Hackman e Oldham (1976) \\
\hline & & Modelo Demanda-Controle da Função & Karasek (1989) \\
\hline & Pessoas & Suporte Social & House (1981) \\
\hline
\end{tabular}

\section{Indivíduo}

No que tange ao indivíduo, teorias originadas na psicologia, tais como a Teoria das Necessidades (Maslow, 1943) e a Teoria da Motivação-Higiene (Herzberg, Mausner, \& Bloc, 1959), foram adaptadas para situações do ambiente de trabalho. O estudo da Psicodinâmica do Trabalho (Dejours, 2004; Dejours, Abdoucheli, \& Jayet, 1993) e, mais recentemente, o desenvolvimento da Psicologia Positiva (Seligman, 2002), com seu foco nas forças que os indivíduos possuem, também trouxeram contribuições relevantes para a questão.

Já no âmbito da economia, os estudos da recente Economia da Felicidade oferecem uma evolução dos conceitos originais da utilidade do trabalho, indo além da retribuição financeira (Frey \& Stutzer, 2002; Graham, 2005; Rätzel, 2012; Spencer, 2014).

\section{Organizações}

A perspectiva organizacional é a mais estudada na área de administração. Foram desenvolvidos conceitos como Qualidade de Vida no Trabalho (QVT) (Bagtasos, 2011; Walton, 1973) e Suporte Organizacional Percebido (Eisenberger, Huntington, Hutchison, \& Sowa, 1986). A QVT tem como objetivo aumentar a produtividade através da melhoria das condições de trabalho, com desdobramentos nas práticas de recursos humanos das organizações. Já sob o ângulo do Suporte Organizacional Percebido, os indivíduos acreditam que a empresa valoriza suas contribuições e se preocupa com sua felicidade, oferecendo recompensas materiais e simbólicas.

A ênfase na influência do desenho da função (job design) também produziu o desenvolvimento de modelos como forma de contrabalançar o legado da Administração Científica. Destacam-se o modelo das Características da Função (Hackman \& Oldham, 1976) e seus desdobramentos (por exemplo, de Morgeson e Humphrey (2006)) e o modelo de Demanda-Controle da Função (Karasek, 1989). Já quanto a relações interpessoais, surgiram modelos ligados ao Suporte Social, sendo o de House (1981) o mais utilizado (Dormann \& Zapf, 1999).

\section{O fit}

Como visto anteriormente, tanto antecedentes ligados ao indivíduo quanto à organização podem impactar a felicidade no trabalho. No entanto, segundo Caldwell e O'Reilly (1990), a interação entre 
eles explica o fenômeno melhor que cada um sozinho. Nesta linha foram desenvolvidos modelos interacionais para entender e prever o comportamento, considerando fatores pessoais e situacionais e como eles se relacionam (Chatman, 1989). Este efeito combinado dos antecedentes ligados ao indivíduo e à organização é denominado fit (Sousa \& Porto, 2015).

$\mathrm{O}$ conceito mais amplo de fit é conhecido como PE fit (person-environment fit) e se refere à coerência ou similaridade entre o indivíduo e o ambiente (Edwards, 2008; O’Reilly, Chatman, \& Caldwell, 1991). Os indivíduos têm experiências positivas quando o trabalho proporciona um ambiente compatível com suas características pessoais (Kristof-Brown, Jansen, \& Colbert, 2002).

Essa adequação é estudada em relação à função, à organização, ao grupo de trabalho, à vocação e à cultura organizacional, conforme apresentado na Tabela 6.

Tabela 6

Tipos de Fit

\begin{tabular}{|c|c|c|}
\hline Fit & & Referências \\
\hline $\begin{array}{l}\text { Person-Organization } \\
\text { Person-Job }\end{array}$ & $\begin{array}{l}P-O \\
P-J\end{array}$ & $\begin{array}{l}\text { Boon, Den Hartog, Boselie e Paauwe (2011); Edwards (2008); Sousa e } \\
\text { Porto (2015); Vogel e Feldman (2009) }\end{array}$ \\
\hline Person-Group & $P-G$ & Kristof-Brown, Jansen e Colbert (2002); Vogel e Feldman (2009) \\
\hline Person-Vocation & $P-V$ & Vogel e Feldman (2009) \\
\hline Person-Culture & $P-C$ & O’Reilly et al. (1991) \\
\hline
\end{tabular}

\section{Lacunas na literatura e oportunidades}

Como visto na revisão apresentada nas seções anteriores, muito já se estudou acerca da felicidade no trabalho. No entanto, o conhecimento gerado pela ampla e abrangente literatura carece de convergência, impossibilitando a visão da questão de forma plena. Em primeiro lugar, não há um consenso acerca do conceito da felicidade em si, existindo uma série de diferentes construtos ligados ao tema, como pôde ser visto anteriormente. No que diz respeito aos antecedentes, essa integração também é deficiente. Os elementos que atuam como antecedentes da felicidade no trabalho, por exemplo, são muitas vezes considerados de forma isolada ou em pequenos grupos.

As teorias e os modelos apresentados neste estudo, por sua vez, proporcionam uma visão mais abrangente do que os estudos que avaliam a relação entre um ou mais elementos e a felicidade no trabalho. Ainda assim, consideram os níveis de análise do indivíduo e da organização de forma isolada, não oferecendo, portanto, um panorama geral da questão. Finalmente, o fit constitui uma iniciativa de integrar as visões do indivíduo e da organização. Porém, este conceito não reflete as influências de cada nível de análise separadamente, apenas a adequação entre eles.

Devido à ausência de integração entre os variados estudos relacionados à felicidade no trabalho, esta área de estudo carece de perspectivas abrangentes que contemplem todos os níveis de análise Indivíduo e Organização (Empresa, Função e Pessoas) - bem como os elementos que identificam os canais de fit entre eles. Em consonância com as lacunas identificadas, este artigo apresenta duas propostas. A primeira diz respeito a usar felicidade no trabalho como um conceito guarda-chuva, englobando todos os construtos ligados a ele, conforme mencionado anteriormente. A segunda se refere ao desenvolvimento de uma perspectiva integrada dos antecedentes da felicidade no trabalho, que supostamente influenciam este estado psicológico do indivíduo. Esta perspectiva integrada é descrita na próxima seção. 


\section{Proposta de Perspectiva Integrada dos Antecedentes}

\section{Perspectiva proposta}

O desenvolvimento de uma perspectiva integrada dos antecedentes da felicidade no trabalho buscou dois propósitos. Primeiramente, incorporar tanto a visão individual (nature) quanto a das organizações (nurture), uma vez que, segundo Davidoff (1983, p. 70), "não faz sentido dizer que a hereditariedade ou meio é mais significativo, pois ambos são absolutamente essenciais". Além disso, procurou propor uma visão abrangente o suficiente para poder acomodar novas descobertas de antecedentes que venham a surgir através de pesquisas futuras. Assim, ao invés de partir dos antecedentes e suas origens, a perspectiva proposta busca colocar o foco no efeito de cada um deles no indivíduo, que é a unidade de análise onde efetivamente se aplica o conceito da felicidade do trabalho. Em outras palavras, o foco é a forma como o indivíduo percebe o seu trabalho, sendo essa percepção influenciada pelos antecedentes.

Dolan (2015) conta em seu livro a história de uma amiga que passou um jantar descrevendo o quanto estava infeliz na prestigiada empresa de comunicação onde trabalhava, reclamando do chefe, dos colegas e do tempo de deslocamento, e que terminou o encontro declarando sinceramente o quanto adorava trabalhar lá. Há várias histórias como esta: pessoas que adoram a tarefa que desempenham, mas não suportam o chefe (W. Jones, 2013); ou que adoram sua atividade, mas não gostam como são tratados na empresa (Wood, 2016); ou, ainda, que adoram a empresa onde trabalham, mas não gostam das atividades que realizam (Levin-Epstein, 2013).

De uma forma geral, podemos resumir essas questões em duas dimensões. A proposta destas duas dimensões, além de derivar da dicotomia apresentada pelos exemplos acima, baseia-se nas ideias de Kahneman e Riis (2005) de que existem duas perspectivas de felicidade: a experimentada e a avaliada.

A primeira dimensão proposta se relaciona à função desempenhada - como o indivíduo experimenta o trabalho. Uma vez que ele passa a maior parte do tempo que dedica ao trabalho desempenhando as atividades inerentes à sua função, a forma como vivencia essas tarefas pode ser considerada uma questão importante para o seu estado geral de felicidade. Esta dimensão será aqui tratada como execução do trabalho - experiência.

A segunda dimensão proposta diz respeito ao contexto - como o indivíduo avalia o trabalho. Esta dimensão considera questões tais como a localização do trabalho, a remuneração, o ambiente social, o horário em que entra ou sai do trabalho, o status da empresa e da função, entre outras, e aqui será resumida como contexto do trabalho - avaliação.

Essas duas dimensões, de forma simplificada, podem levar a quatro situações do indivíduo em relação ao trabalho: (1) gosta do que faz e está bem onde está; (2) não gosta do que faz, mas está bem onde está; (3) gosta do que faz, mas não está bem onde está; e (4) não gosta do que faz e não está bem onde está. Estas quatro situações são ilustradas na Figura 1. 


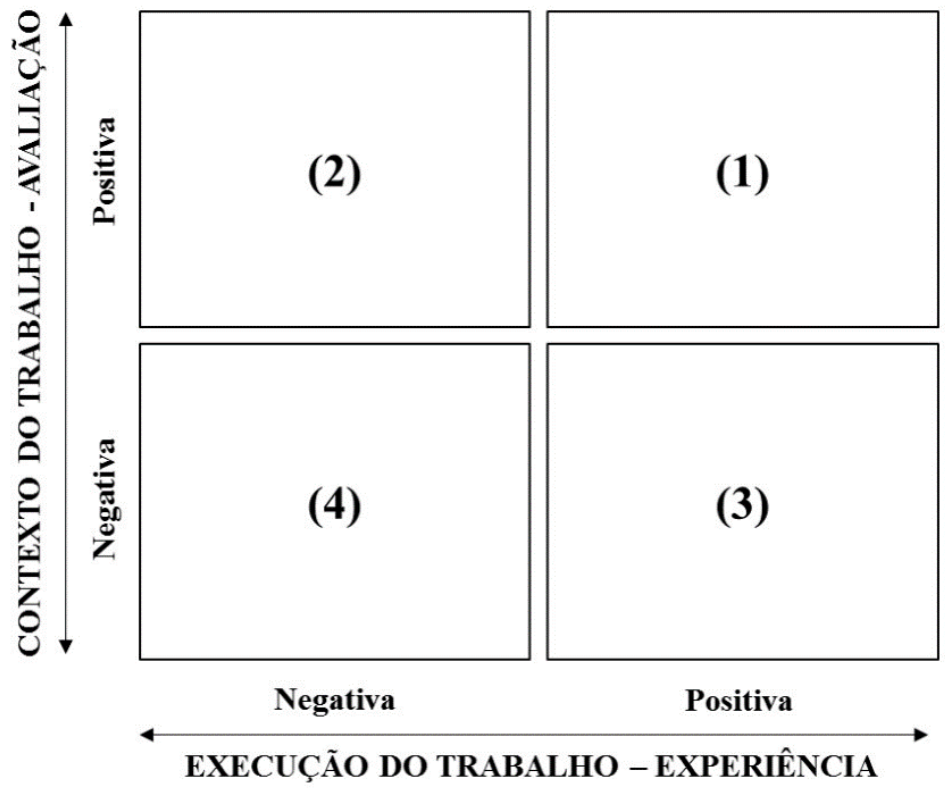

Figura 1. Perspectiva Integrada dos Antecedentes da Felicidade no Trabalho e Comportamentos Derivados.

As quatro situações apresentadas na Figura 1 representam diferentes estados psicológicos em relação à felicidade no trabalho, que levam a diversos comportamentos por parte dos indivíduos, com múltiplas consequências para as organizações.

As situações (1) e (4) são de interpretação mais direta. A situação (1), na qual o indivíduo gosta do que faz e está bem onde está, pode ser considerada um estado feliz, quando surgem comportamentos positivos para a organização, tais como uma expansão da sua atuação além do papel previsto, proatividade e uma melhor adaptabilidade (Macey \& Schneider, 2008). Além disso, os indivíduos ficam mais sensíveis a oportunidades, mais dispostos a ajudar os colegas e mais confiantes (Zelenski, Murphy, \& Jenkins, 2008), o que pode, por sua vez, acarretar os impactos positivos de resultados apresentados na seção referente aos impactos da felicidade no trabalho.

Já a situação (4), em que o indivíduo não gosta do que faz e não está bem onde está, levaria a um estado infeliz. Como consequência, tal indivíduo tenderia a ter menos energia, tomar decisões de pior qualidade e reduzir sua produtividade e sua contribuição para a organização. Este estado poderia desencadear também um aumento do nível de absenteísmo e da quantidade de licenças devido a estafa e outras doenças. No limite, pode levar à decisão de uma mudança de trabalho (turnover) (Danna \& Griffin, 1999; Lok \& Crawford, 2004; Warr, 2007; Zelenski et al., 2008). Baixa produtividade, desempenho ruim, absenteísmo e turnover são comportamentos negativos para a organização.

As situações (2) e (3) são estados intermediários, nas quais o comportamento dependeria das características individuais. Assim, para uma mesma situação (2), indivíduos que valorizam mais o contexto do que a experiência poderiam ter comportamentos positivos mesmo não gostando do que fazem, caso estejam felizes onde estão, enquanto indivíduos que valorizam mais a experiência do que o contexto teriam comportamentos negativos. A situação 3 funcionaria de forma inversa - indivíduos que valorizam mais o contexto teriam comportamentos negativos e aqueles que valorizam mais a experiência teriam comportamentos positivos.

Em ambas as situações, no entanto, caso o equilíbrio entre as dimensões ficasse desbalanceado por exemplo, mesmo que o indivíduo valorize mais o contexto, a execução da tarefa é tão ruim que minimizaria ou anularia o aspecto positivo deste contexto - o comportamento poderia ser neutro ou, ainda, negativo. 


\section{Integração dos antecedentes}

A perspectiva proposta anteriormente procura integrar os antecedentes apresentados neste estudo, conforme a Figura 2.

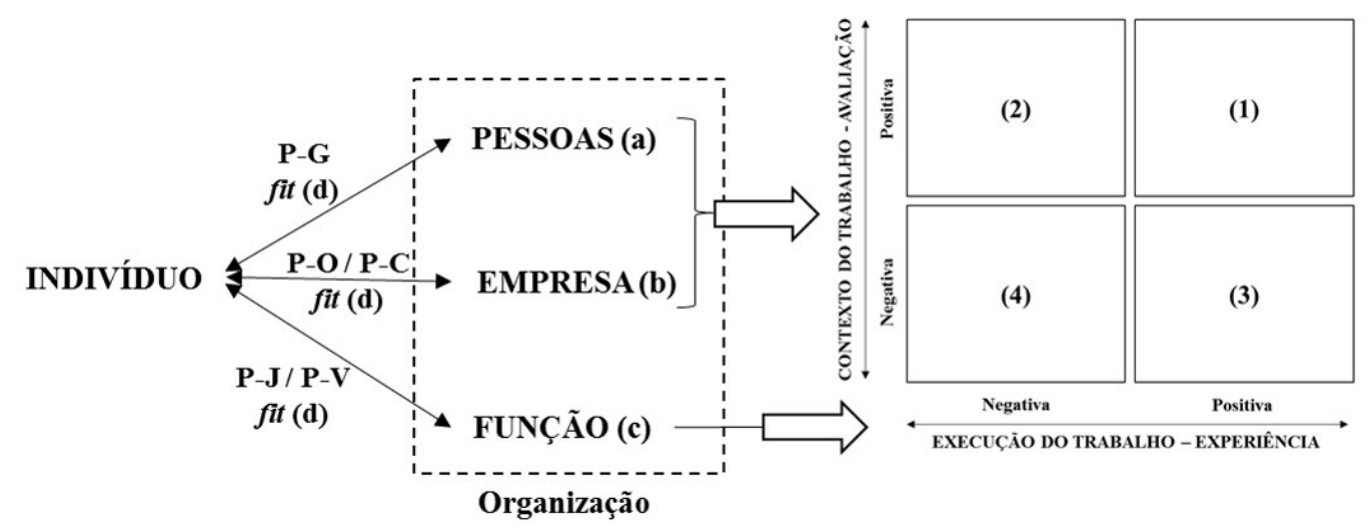

Figura 2. Relação entre os Antecedentes e as Dimensões Propostas na Perspectiva Integrada (1) $\mathrm{P}-\mathrm{G}=$ Person-Group $; \mathrm{P}-\mathrm{O}=$ Person-Organization; $\mathrm{P}-\mathrm{C}=$ Person-Culture; $\mathrm{P}-\mathrm{J}=$ Person-Job; $\mathrm{P}-\mathrm{V}=$ Person Vocation; (2) As sinalizações (a), (b), (c), (d) e (e).

Os níveis de análise ligados à Organização (Pessoas, Empresa e Função) se integram diretamente às duas dimensões propostas.

Os antecedentes ligados à Empresa e às Pessoas (sinalizadas respectivamente como (a) e (b) na Figura 2) influenciam a forma como o indivíduo avalia o contexto do seu trabalho (Contexto do Trabalho - Avaliação). Esses níveis de análise englobam elementos tais como oportunidades de desenvolvimento, condições físicas, jornada de trabalho, remuneração e relações com gestores e com as demais pessoas, além das teorias de Qualidade de Vida Total (Walton, 1973), Suporte Organizacional Percebido (Eisenberger et al., 1986) e Suporte Social (House, 1981).

Já os antecedentes da Função (c) têm impacto na experiência vivenciada pelo indivíduo na execução da sua atividade (Execução do Trabalho - Experiência). Esse nível de análise corresponde aos elementos ligados à forma como a função é desenhada (com menor ou maior autonomia, variedade de atividades, complexidade) e o indivíduo realiza tal função na prática (modificando-a para torná-la mais prazerosa). Refere-se também aos modelos das Características da Função (Hackman \& Oldham, 1975), de Demanda-Controle (Karasek, 1989) e de Fluxo (Csikszentmihalyi, 1991).

Os antecedentes ligados aos Fits (sinalizados com (d) na Figura 2) indicam de que forma as suas características pessoais se relacionam tanto com o trabalho executado quanto com o contexto. Assim, os diferentes fits influenciam o ponto em que o indivíduo será posicionado na matriz, levando ao fato de que, em situações concretas semelhantes, indivíduos diferentes podem estar em posições distintas, uma vez que podem avaliar e experimentar o trabalho de forma diversa. Tome-se como exemplo dois indivíduos em uma mesma empresa, em uma mesma equipe (relacionando-se com as mesmas pessoas) e desempenhando a mesma função - eles podem, no entanto, se situar em quadrantes distintos. Uma melhor ou pior adequação de suas características individuais com as características da função (P-J e PV fit), da empresa (P-O e P-C fit) e das pessoas (P-G fit) influenciaria a percepção das duas dimensões propostas e, consequentemente, resultaria em um posicionamento distinto na matriz da Figura 1.

Os antecedentes ligados ao Indivíduo (e), por sua vez, influenciam os comportamentos derivados do posicionamento na matriz, conforme apresentado na descrição das situações (2) e (3) na seção anterior.

RAC, Rio de Janeiro, v. 21, n. 6, art. 2, pp. 764-787, Novembro/Dezembro, 2017, www.anpad.org.br/rac (co) Eү 


\section{Conclusões}

Segundo Saks e Gruman (2014, p. 178), "o frenesi de pesquisas" sobre a felicidade no trabalho deixou uma série de perguntas importantes sem respostas claras e sem consenso. As várias pesquisas realizadas, como as citadas neste artigo, buscam definir o significado e propor medidas no que tange à felicidade no trabalho; entender os efeitos nos resultados das empresas; e identificar o que influencia tal estado, especialmente no que diz respeito ao que a empresa pode (ou não) fazer neste sentido.

Por outro lado, observam-se vozes dissonantes quanto a essa questão, principalmente em publicações mais ligadas à prática como as presentes nas revistas Harvard Business Review, The Economist e GV executivo. Alguns artigos apontam aspectos negativos ligados à pressão da busca da felicidade no trabalho, que torna tal busca obrigatória e artificial, enquanto outros afirmam que as organizações não são locais onde se deve buscar a felicidade (Bendassolli, 2007; Spicer \& Cederström, 2015; Wooldridge, 2016), aumentando, desta forma, as divergências existentes acerca do tema.

Neste contexto de falta de respostas concretas acerca do papel da felicidade no trabalho e de seus efeitos nas organizações, a evolução do conhecimento científico é fundamental para apoiar as empresas na tomada de decisões acerca da gestão de recursos humanos, muitas das quais impactam os custos. Portanto, o tópico felicidade no trabalho deve permanecer na agenda da pesquisa de estudos organizacionais.

Ao propor uma perspectiva que procura integrar e convergir o conhecimento existente, o presente artigo oferece um quadro de análise para o desenvolvimento futuro deste tema. A proposta aqui apresentada possibilita o emprego de perspectivas mais abrangentes em novos estudos, podendo também facilitar a identificação de lacunas da literatura e caminhos de pesquisa. A título de exemplo, novos antecedentes que venham a ser identificados podem ser alinhados a uma das dimensões apresentadas. $\mathrm{Ou}$, ainda, a presença e/ou intensidade de determinada consequência da felicidade no trabalho pode ser relacionada a um dos quadrantes propostos.

Esta perspectiva, no entanto, pode e deve ser refinada, principalmente em torno de questões que permitam expandi-la em outros níveis. Uma questão a ser aprofundada se refere às diferenças de comportamento dos indivíduos, principalmente quando o estado psicológico derivado da influência dos antecedentes resultar em situações como a (2) e a (3) na matriz da Figura 1.

Outra questão a ser incluída diz respeito à influência do ambiente mais amplo, além das questões organizacionais tratadas neste artigo. Segundo Lok e Crawford (2004), por exemplo, a cultura nacional influencia a felicidade no trabalho e o comportamento dos indivíduos. Essa influência deriva da diferença de estilos de liderança e de cultura organizacional em diferentes locais geográficos. Ainda no que diz respeito ao ambiente, Frey e Stutzer (2002) sustentam que a felicidade seria também influenciada por fatores macroeconômicos (como desemprego, renda e inflação) e políticos (como a participação da população e o grau de descentralização do governo).

Para evoluir a perspectiva apresentada, também seria importante verificar a aplicação desses conceitos através de um estudo de campo em profundidade, analisando as dimensões propostas, incorporando as questões anteriores e verificando as conexões dos antecedentes com o comportamento dos indivíduos e os efeitos deste comportamento no desempenho das organizações.

\section{Agradecimentos}

As autoras agradecem os valiosos comentários e sugestões efetuados pelos avaliadores. A realização do estudo contou com o apoio do CNPq, sob o processo número 309771/2015-3. 


\section{Referências}

Albuquerque, A. S., \& Tróccoli, B. T. (2004). Desenvolvimento de uma escala de bem-estar subjetivo. Psicologia: Teoria e Pesquisa, 20(2), 153-164. http://dx.doi.org/10.1590/S010237722004000200008

Ambrose, M. L., \& Kulik, C. T. (1999). Old friends, new faces: Motivation research in the 1990s. Journal of Management, 25(3), 231-292. http://dx.doi.org/10.1016/S0149-2063(99)00003-3

Ariely, D. (2013). What make us feel good about work? Retrieved July 9, 2016, from https://www.ted.com/talks/dan_ariely_what_makes_us_feel_good_about_our_work/transcript

Aronsson, G. (1989). Dimensions of control as related to work organization, stress, and health. International Journal of Health Services, 19(3), 459-468. http://dx.doi.org/10.2190/N6KQHWA0-H7CJ-KUPQ

Arvey, R. D., Bouchard, T. J., Segal, N. L., \& Abraham, L. M. (1989). Job satisfaction: Environmental and genetic components. Journal of Applied Psychology, 74(2), 187-192. http://dx.doi.org/10.1037/0021-9010.74.2.187

Bagtasos, M. R. (2011). Quality of work life: A review of literature. DLSU Business \& Economics Review, 20(2), 1-8. http://dx.doi.org/10.3860/ber.v20i2.1909

Baruch, Y. (2006). Career development in organizations and beyond: Balancing traditional and contemporary viewpoints. Human Resource Management Review, 16(2), 125-138. http://dx.doi.org/10.1016/j.hrmr.2006.03.002

Bellah, R. N., Madsen, R., Sullivan, W. M., Swidler, A., \& Tipton, S. M. (1985). Habits of the heart: Individualism and commitment in American life. Los Angeles: University of California Press.

Bendassolli, P. F. (2007). Felicidade e trabalho. GV Executivo, 6(4), 56-61. http://dx.doi.org/10.12660/gv-executivo.v6i4.34637

Boon, C., Den Hartog, D. N., Boselie, P., \& Paauwe, J. (2011). The relationship between perceptions of HR practices and employee outcomes: examining the role of person-organisation and person-job fit. The International Journal of Human Resource Management, 22(1), 138-162. http://dx.doi.org/10.1080/09585192.2011.538978

Bose, I., \& Sampath, S. (2016). Workers' perception to job security: An empirical study on the organized leather industry in Kolkata, India. Skyline Business Journal, 11(1), 12-21.

Boxx, W. R., Odom, R. Y., \& Dunn, M. G. (1991). Organizational values and value congruency and their impact on satisfaction, commitment, and cohension: An empirical examination within the public sector. Public Personnel Management, 20(1), 195-205. http://dx.doi.org/10.1177/009102609102000207

Brannigan, A., \& Zwerman, W. (2001). The real "Hawthorne effect." Society, 38(2), 55-60. http://dx.doi.org/10.1007/s12115-001-1041-6

Brayfield, A. H., \& Crockett, W. H. (1955). Employee attitudes and employee performance. Psychological Bulletin, 52(2), 396-424. http://dx.doi.org/10.1037/h0045899

Caldwell, D. F., \& O'Reilly, C. A. (1990). Measuring person job fit with a profile-comparison process. Journal of Applied Psychology, 75(6), 648-657. http://dx.doi.org/10.1037/0021-9010.75.6.648 
Carasco-Saul, M., Kim, W., \& Kim, T. (2015). Leadership and employee engagement: Proposing research agendas through a review of literature. Human Resource Development Review, 14(1), 38-63. http://dx.doi.org/10.1177/1534484314560406

Cartwright, S., \& Holmes, N. (2006). The meaning of work: The challenge of regaining employee engagement and reducing cynicism. Human Resource Management Review, 16(2), 199-208. http://dx.doi.org/10.1016/j.hrmr.2006.03.012

Chatman, J. A. (1989). Improving interactional organizational research: A model of person-organization fit. Academy of Management Review, 14(3), 333-349. http://dx.doi.org/10.5465/AMR.1989.4279063

Csikszentmihalyi, M. (1991). Flow: The psychology of optimal experience. New York: Harper \& Row.

Danna, K., \& Griffin, R. (1999). Health and well-being in the workplace: A review and synthesis of the $\begin{array}{llll}\text { literature. Journal } & \text { 357-384. }\end{array}$ http://dx.doi.org/10.1177/014920639902500305

Davidoff, L. L. (1983). Introdução à psicologia. São Paulo: Makron Books do Brasil.

Dejours, C. (2004). A metodologia em psicodinâmica do trabalho. In S. Lancman \& L. Sznelwar (Orgs.), Christophe Dejours: Da psicopatologia à psicodinâmica do trabalho (pp. 105-126). Rio de Janeiro: Fiocruz.

Dejours, C., Abdoucheli, E., \& Jayet, C. (1993). Psicodinâmica do trabalho - Contribuições da escola dejouriana à análise da relação prazer, sofrimento e trabalho. São Paulo: Atlas.

Diener, E. (1984). Subjective well being. Psychological Bulletin, 95(3), 542-575.

Dolan, P. (2015). Felicidade construída. Rio de Janeiro: Editora Objetiva.

Dolan, P., Peasgood, T., \& White, M. (2008). Do we really know what makes us happy? A review of the economic literature on the factors associated with subjective well-being. Journal of Economic Psychology, 29(1), 94-122. http://dx.doi.org/10.1016/j.joep.2007.09.001

Dormann, C., \& Zapf, D. (1999). Social stressors at work, irritation, and depressive symptoms: Accounting for unmeasured third variables in a multi-wave study. Journal of Applied Psychology, 84(6), 874-884. http://dx.doi.org/10.1348/096317902167630

Edwards, J. R. (2008). Person-environment fit in organizations: An assessment of theoretical progress. The Academy of Management Annals, 2(1), 167-230. http://dx.doi.org/10.1080/19416520802211503

Eisenberger, R., Huntington, R., Hutchison, S., \& Sowa, D. (1986). Perceived organizational support. Journal of Applied Psychology, 71(3), 500-507. http://dx.doi.org/10.1037/0021-9010.71.3.500

Elsevier. (n.d.). Scopus database. Retrieved August 30, 2016, from http://www.sciencedirect.com/science/search

Fernandes, K. R., \& Zanelli, J. C. (2006). O processo de construçăo e reconstruçăo das identidades dos indivíduos nas organizaçőes. Revista de Administração Contemporânea, 10(1), 55-72. http://dx.doi.org/10.1590/S1415-65552006000100004

Fisher, C. D. (2003). Why do lay people believe that satisfaction and performance are correlated? Possible sources of a commonsense theory. Journal of Organizational Behavior, 24(6), 753-777. http://dx.doi.org/10.1002/job.219 
Fisher, C. D. (2010). Happiness at work. International Journal of Management Reviews, 12(4), 384412. http://dx.doi.org/10.1111/j.1468-2370.2009.00270.x

Frankl, V. E. (1984). Man's search for meaning. New York: Washington Square Press Publication.

Frey, B., \& Stutzer, A. (2002). The economics of happiness. World Economics, 3(1), 1-17. http://dx.doi.org/10.1162/001152604323049361

Gagné, M., \& Deci, E. L. (2005). Self-determination theory and work motivation. Journal of Organizational Behavior, 26(4), 331-362. Retrieved from http://dx.doi.org/10.0.3.234/job.322

Gallup. (2013). The state of the American workplace: Employee engagement insights for U.S. business leaders. gallup. Retrieved from http://employeeengagement.com/wpcontent/uploads/2013/06/Gallup-2013-State-of-the-American-Workplace-Report.pdf

Ganzach, Y. (1998). Intelligence and job satisfaction. Academy of Management Journal, 41(5), 526539. http://dx.doi.org/10.2307/256940

Given, L. M. (Ed.). (2008). The SAGE encyclopedia of qualitative research methods. Thousand Oaks, USA: SAGE. http://dx.doi.org/10.4135/9781412963909

Graham, C. (2005). The economics of happiness: Insights on globalization from a novel approach. World Economics, 6(3), 41-55. http://dx.doi.org/10.1093/wbro/lki010

Hackman, J. R., \& Oldham, G. R. (1975). Development of the job diagnostic survey. Journal of Applied Psychology, 60(2), 159-170. http://dx.doi.org/10.1037/h0076546

Hackman, J. R., \& Oldham, G. R. (1976). Motivation through the design of work: Test of a theory. Organizational Behavior and Human Performance, 16(2), 250-279. http://dx.doi.org/10.1016/0030-5073(76)90016-7

Handa, M., \& Gulati, A. (2014). Employee engagement - Does individual personality matter. Journal of Management Research, 14(1), 57-67. http://dx.doi.org/10.1002/ert

Harter, J. K., Schmidt, F. L., \& Hayes, T. L. (2002). Business-unit-level relationship between employee satisfaction, employee engagement, and business outcomes: A meta-analysis. Journal of Applied Psychology, 87(2), 268-279. http://dx.doi.org/10.1037//0021-9010.87.2.268

Herzberg, F., Mausner, B., \& Bloc, B. (1959). The motivation to work. New York: Wiley.

Hoppock, R. (1935). Job satisfaction. New York: Harper and Brothers.

House, J. S. (1981). Work stress and social support. London: Addison-Wesley Educational Publishers Inc.

Hughes, J. C., \& Rog, E. (2008). Talent management: A strategy for improving employee recruitment, retention and engagement within hospitality organizations. International Journal of $\begin{array}{llll}\text { Contemporary } \quad \text { Hospitality } & \text { 743-757. }\end{array}$ http://dx.doi.org/10.1108/09596110810899086

Ilies, R., \& Judge, T. A. (2003). On the heritability of job satisfaction: The mediating role of personality. Journal of Applied Psychology, 88(4), 750-759. http://dx.doi.org/10.1037/0021-9010.88.4.750

Johansson, G. (1989). Job demands and stress reactions in repetitive and uneventful monotony at work. International Journal of Health Services, 19(2), 365-377. http://dx.doi.org/10.2190/XYP9VK4Y-9H80-VV3K

Johnson, J. V. (1989). Collective control: Strategies for survival in the workplace. International Journal of Health Services, 19(3), 469-480. http://dx.doi.org/10.2190/H1D1-AB94-JM7X-DDM4

RAC, Rio de Janeiro, v. 21, n. 6, art. 2, pp. 764-787, Novembro/Dezembro, 2017, www.anpad.org.br/rac (co) EY 
Jones, M. K., Jones, R. J., Latreille, P. L., \& Sloane, P. J. (2009). Training, job satisfaction and workplace performance in Britain: Evidence from WERS 2004. LABOUR, 23(s1), 139-175. http://dx.doi.org/10.1111/j.1467-9914.2008.00434.x

Jones, R. (2016, July 19). The family dynamics we grew up with shape how we work. Retrieved July 23, 2016, from https://hbr.org/2016/07/the-family-dynamics-we-grew-up-with-shape-how-we-work

Jones, W. (2013, March 6). The common conundrum: What to do when you love your job but hate your boss. Retrieved September 8, 2016, from http://www.businessinsider.com/the-commonconundrum-what-to-do-when-you-love-your-job-but-hate-your-boss-2013-3

Judge, T. A., Heller, D., \& Mount, M. K. (2002). Five-factor model of personality and job satisfaction. Journal of Applied Psychology, 87(3), 530-541. http://dx.doi.org/10.1037/0021-9010.87.3.530

Kahn, W. A. (1990). Psychological conditions of personal engagement and disengagement at work. Academy of Management Journal, 33(4), 692-724. http://dx.doi.org/10.2307/256287

Kahneman, D., \& Riis, J. (2005). Living, and thinking about it: Two perspectives on life. In B. K. F. A. Huppert \& N. Baylis (Eds.), The science of well-being (pp. 285-304). New York: Oxford University Press. http://dx.doi.org//10.1093/acprof:oso/9780198567523.003.0011

Karasek, R. (1989). The political implications of psychosocial work redesign: A model of the psychosocial class structure. International Journal of Health Services, 19(3), 481-508. http://dx.doi.org/10.2190/66AM-Q4PF-PUHK-5BT1

Kets de Vries, M. F. R., \& Balazs, K. (1997). The downside of downsizing. Human Relations, 50(1), 11-50. http://dx.doi.org/10.1177/001872679705000102

Kirmeyer, S. L., \& Lin, T. (1987). Social support: Its relationship to observed communication with peers and superiors. Academy of Management Journal, 30(1), 138-151. http://dx.doi.org/10.2307/255900

Kristof-Brown, A. L., Jansen, K. J., \& Colbert, A. E. (2002). A policy-capturing study of the simultaneous effects of fit with jobs, groups, and organizations. Journal of Applied Psychology, 87(5), 985-993. http://dx.doi.org/10.5465/APBPP.2001.27461493

Ledford, G. E., Jr. (1999). Happiness and productivity revisited. Journal of Organizational Behavior, 20(1), 25-30. http://dx.doi.org/10.1002/(sici)1099-1379(199901)20:1<25::aid-job913>3.0.co;2-k

Lennerlöf, L. (1988). Learned helplessness at work. International Journal of Health Services, 18(2), 207-222. http://dx.doi.org/10.2190/CPFB-Y04Y-5DCM-YX7F

Leslie, L. M., Manchester, C. F., Park, T.-Y., \& Mehng, S. A. (2012). Flexible work practices: A source of career premiums or penalties? Academy of Management Journal, 56(6), 1407-1429. http://dx.doi.org/10.5465/amj.2010.0651

Levin-Epstein, A. (2013). Hate your job but love your company? Retrieved September 8, 2016, from http://www.cbsnews.com/news/hate-your-job-but-love-your-company/

Li, A. N., \& Liao, H. (2014). How do leader-member exchange quality and differentiation affect performance in teams? An integrated multilevel dual process model. Journal of Applied Psychology, 99(5), 847-866. http://dx.doi.org/10.1037/a0037233

Locke, E. A. (1969). What is job satisfaction? Organizational Behavior and Human Performance, 4(4), 309-336. http://dx.doi.org/10.1016/0030-5073(69)90013-0

Lodahl, T. M., \& Kejnar, M. (1965). The definition and measurement of job involvement. Journal of Applied Psychology, 49(1), 24-33. http://dx.doi.org/10.1037/h0021692 
Lok, P., \& Crawford, J. (2004). The effect of organisational culture and leadership style on job satisfaction and organisational commitment: A cross-national comparison. Journal of Management Development, 23(4), 321-338. http://dx.doi.org/10.1108/02621710410529785

Lund, D. B. (2003). Organizational culture and job satisfaction. Journal of Business Industrial Marketing, 18(2/3), 219-236. http://dx.doi.org/10.1108/0885862031047313

Lykken, D., \& Tellegen, A. (1996). Happiness is a stochastic phenomenon. American Psychological Science, 7(3), 186-189. http://dx.doi.org/10.1111/j.1467-9280.1996.tb00355.x

Macey, W. H., \& Schneider, B. (2008). The meaning of employee engagement. Industrial and Organizational Psychology, 1(1), 3-30. http://dx.doi.org/10.1111/j.1754-9434.2007.0002.x

Maslow, A. H. (1943). A theory of human motivation. Psychological Review, 50(13), 370-396. http://dx.doi.org/10.1037/h0054346

Morgeson, F. P., \& Humphrey, S. E. (2006). The work design questionnaire (WDQ): Developing and validating a comprehensive measure for assessing job design and the nature of work. Journal of Applied Psychology, 91(6), 1321-1339. http://dx.doi.org/10.1037/0021-9010.91.6.1321

Morin, E. (2001). Os sentidos do trabalho. Revista de Administração de Empresas, 41(3), 8-19. http://dx.doi.org/10.1590/S0034-75902001000300002

Morin, E., Tonelli, M. J., \& Pliopas, A. L. V. (2007). O trabalho e seus sentidos [Edição Especial]. Psicologia \& Sociedade, 19, 47-56. http://dx.doi.org/10.1590/S0102-71822007000400008

Mowday, R. T., Porter, L. W., \& Steers, R. M. (1982). Employee-organization linkages: The psychology of commitment, absenteeism, and turnover. New York: Academic Press.

Mowday, R. T., Steers, R. M., \& Porter, L. W. (1996). The measurement of organizational commitment and professional commitment. The Journal of Social Psychology, 136(2), 265-267. http://dx.doi.org/10.1080/00224545.1996.9714004

Odom, R. Y., Boxx, W. R., \& Dunn, M. G. (1990). Organizational cultures, commitment, satisfaction, and cohesion. Public Productivity \& Management Review, 14(2), 157-169. http://dx.doi.org/10.2307/3380963

Oliveira, L., Cavazotte, F., \& Paciello, R. R. (2013). Antecedentes e consequências dos conflitos entre trabalho e família. Revista de Administração Contemporânea, 17(4), 418-437. Recuperado de http://www.scielo.br/pdf/rac/v17n4/a03v17n4.pdf. $\quad$ http://dx.doi.org/10.1590/S141565552013000400003

O’Reilly, C. A., Chatman, J., \& Caldwell, D. F. (1991). People and organizational culture: A profile comparison approach to assessing person-organization fit. Academy of Management Journal, 34(3), 487-516. http://dx.doi.org/10.2307/256404

Paschoal, T., \& Tamayo, A. (2008). Construção e validação da escala de bem-estar no trabalho. Avaliação Psicológica, 7(1), 11-22. Recuperado de http://pepsic.bvsalud.org/scielo.php?script=sci_arttext\&pid=S1677-

$04712008000100004 \& \operatorname{lng}=\mathrm{pt} \& \operatorname{lng}=\mathrm{pt}$

Paschoal, T., Torres, C. V., \& Porto, J. B. (2010). Felicidade no trabalho: Relações com suporte organizacional e suporte social. Revista de Administração Contemporânea, 14(6), 1054-1072. Recuperado de http://www.scielo.br/pdf/rac/v14n6/v14n6a05.pdf. http://dx.doi.org/10.1590/S1415-65552010000700005

Rätzel, S. (2012). Labour supply, life satisfaction, and the (dis)utility of work. Scandinavian Journal of Economics, 114(4), 1160-1181. http://dx.doi.org/10.1111/j.1467-9442.2012.01717.x

RAC, Rio de Janeiro, v. 21, n. 6, art. 2, pp. 764-787, Novembro/Dezembro, 2017, www.anpad.org.br/rac (oc)) 
Rosso, B. D., Dekas, K. H., \& Wrzesniewski, A. (2010). On the meaning of work: A theoretical integration and review. Research in Organizational Behavior, 30, 91-127. http://dx.doi.org/10.1016/j.riob.2010.09.001

Saks, A. M., \& Gruman, J. A. (2014). What do we really know about employee engagement? Human Resource Development Quaterly, 25(2), 155-182. http://dx.doi.org/10.1002/hrdq

Sant'anna, L. L., Paschoal, T., \& Gosendo, E. E. M. (2012). Bem-estar no trabalho: Relações com estilos de liderança e suporte para ascensão, promoção e salários. Revista de Administração Contemporânea, 16(5), 744-764. Recuperado de http://www.scielo.br/pdf/rac/v16n5/v16n5a07.pdf. $\quad$ http://dx.doi.org/10.1590/S141565552012000500007

Schnittker, J. (2008). Happiness and success: Genes, families, and the psychological effects of socioeconomic position and social support. American Journal of Sociology, 114(S1), S233-S259. http://dx.doi.org/10.1086/592424

Schwartz, B. (2015a). The way we think about work is broken. Retrieved July 9, 2016, from https://www.ted.com/talks/barry_schwartz_the_way_we_think_about_work_is_broken

Schwartz, B. (2015b). Why we're so unhappy with work. Retrieved July 9, 2016, from https://www.linkedin.com/pulse/why-were-so-unhappy-work-how-fix-barry-schwartz

Seligman, M. E. P. (2002). Authentic happiness: Using the new positive psychology to realize your potential for lasting fulfillment. New York: Free Press.

Shuck, B., Reio, T. G., \& Rocco, T. S. (2011). Employee engagement: An examination of antecedent and outcome variables. Human Resource Development International, 14(4), 427-445. http://dx.doi.org/10.1080/13678868.2011.601587

Smith, A. (1776). An inquiry into the nature and the causes of the wealth of nations (Vol. 2). London: W. Strahan, and T. Cadell.

Sosis, C. (2014). Hedonic possibilities and heritability statistics. Philosophical Psychology, 27(5), 681702. http://dx.doi.org/10.1080/09515089.2013.764563

Sousa, J. M. de, \& Porto, J. B. (2015). Happiness at work: Organizational values and personorganization fit impact. Paidéia, 25(61), 211-220. http://dx.doi.org/10.1590/198243272561201509

Spector, P. E., \& Jex, S. M. (1998). Development of four self-report measures of job stressors and strain: Interpersonal conflict at work scale, organizational constraints scale, quantitative workload inventory, and physical symptoms inventory. Journal of Occupational Health Psychology, 3(4), 356-367. http://dx.doi.org/10.1037/1076-8998.3.4.356

Spencer, D. A. (2014). Conceptualising work in economics: Negating a disutility. Kyklos, 67(2), 280294. http://dx.doi.org/10.1111/kykl.12054

Spicer, A., \& Cederström, C. (2015). The research we've ignored about happiness at work. Harvard Business Review. Retrieved from https://hbr.org/2015/07/the-research-weve-ignored-abouthappiness-at-work

Staw, B. M., Bell, N. E., \& Clausen, J. A. (1986). The dispositional approach to job attitudes: A lifetime longitudinal test. Administrative Science Quarterly, 31(1), 56-77. http://dx.doi.org/10.2307/2392766 
Staw, B. M., \& Ross, J. (1985). Stability in the midst of change - a dispositional approach to jobattitudes. Journal of Applied Psychology, 70(3), 469-480. http://dx.doi.org/10.1037/00219010.70.3.469

Swailes, S. (2002). Organizational commitment: A critique of the construct and measures. International Journal of Management Reviews, 4(2), 155-178. http://dx.doi.org/10.1111/1468-2370.00082

Taylor, F. W. (1990). Princípios de administração científica. São Paulo: Atlas.

Vogel, R. M., \& Feldman, D. C. (2009). Integrating the levels of person-environment fit: The roles of vocational fit and group fit. Journal of Vocational Behavior, 75(1), 68-81. http://dx.doi.org/10.1016/j.jvb.2009.03.007

Walton, R. E. (1973). Quality of working life: What is it? Sloan Management Review, 15(1), 11-21.

Warr, P. (2007). Work, happiness, and unhappiness. New Jersey: Psychology Press.

Weiss, H. M., \& Cropanzano, R. (1996). Affective events theory: A theoretical discussion of the structure, causes and consequences of affective experiences at work. In B. M. Staw \& L. L. Cummings (Orgs.), Research in organizational behavior: an annual series of analytical essays and critical reviews (Vol. 18, pp. 1-74). Greenwich, CT: JAI.

Wickert, F. R. (1951). Turnover and employees' feelings of ego involvement in the day-to-day operations of a company. Personnel Psychology, 4(2), 185-197. http://dx.doi.org/10.1111/j.17446570.1951.tb01472.x

Wood, Z. (2016, July 31). "Love the job, hate the way we"re treated': Life on the frontline of UK's delivery army. Retrieved September 8, 2016, from https://www.theguardian.com/money/2016/jul/30/job-pay-workers-gig-economy

Wooldridge, A. (2016, September 24). Against happiness. The Economist. Retrieved September 24, 2016, from https://www.economist.com/news/business-and-finance/21707502-companies-tryturn-happiness-management-tool-are-overstepping-mark

Wright, T. A., \& Huang, C.-C. (2012). The many benefits of employee well-being in organizational research. Journal of Organizational Behavior, 33(8), 1188-1192. http://dx.doi.org/10.1002/job.1828

Wright, T. A., \& Staw, B. M. (1999a). Affect and favorable work outcomes: Two longitudinal tests of the happy-productive worker thesis. Journal of Organizational Behavior, 20(1), 1-23. Retrieved from http://onlinelibrary.wiley.com/doi/10.1002/(SICI)1099-1379(199901)20:1\%3C1::AIDJOB885\%3E3.0.CO;2-W/full. http://dx.doi.org/10.1002/(SICI)1099-1379(199901)20:1<1::AIDJOB885>3.0.CO;2-W

Wright, T. A., \& Staw, B. M. (1999b). Further thoughts on the happy - productive worker. Journal of Organizational Behavior, 20(1), 31-34. http://dx.doi.org/10.1002/(SICI)10991379(199901)20:1<31::AID-JOB952>3.0.CO;2-U

Wrzesniewski, A., \& Dutton, J. E. (2001). Crafting a job: As active employees revisioning crafters of their work. Academy of Management Review, 26(2), 179-201. http://dx.doi.org/10.2307/259118

Wrzesniewski, A., McCauley, C., Rozin, P., \& Schwartz, B. (1997). Jobs, careers, and callings: People's relations to their work. Journal of Research in Personality, 31(1), 21-33. http://dx.doi.org/10.1006/jrpe.1997.2162

Zelenski, J. M., Murphy, S. A., \& Jenkins, D. A. (2008). The happy-productive worker thesis revisited. Journal of Happiness Studies, 9(4), 521-537. http://dx.doi.org/10.1007/s10902-008-9087-4 


\section{Dados dos Autores}

Gisela Sender

Rua Pascoal Lemme, 355, Ilha do Fundão, Cidade Universitária, 21941-918, Rio de Janeiro, RJ, Brasil. E-mail: gisela.sender@coppead.ufrj.br

Denise Fleck

Rua Pascoal Lemme, 355, Ilha do Fundão, Cidade Universitária, 21941-918, Rio de Janeiro, RJ, Brasil. E-mail: denise@ coppead.ufrj.br 